\title{
Comunidades virtuais como ambientepotencializador de estratégias mercadológicas: locus de informações e troca de experiências vivenciadas
}

Nélsio Rodrigues de Abreu

\author{
Professor Adjunto II da Faculdade \\ deEconomia , Administração e \\ Contabilidade - FEAC/UFAL
}

Renata Francisco Baldanza

Docente nos cursos de Comunicação do Instituto de Ciências Humanas,

Ricardo de Souza Sette Comunicação e Artes- ICHCA/UFAL

\section{Professor Titular do Departamento de Administração e Contabilidade- UFAL}

Esta pesquisa objetivou investigar a potencialidade da utilização de comunidades virtuais como fonte de informações para estratégias mercadológicas no setor de turismo. Utilizou-se uma pesquisa qualitativa com grupos focais on-line. Os resultados demonstraram que, através de colaboração espontânea, as pessoas trocam experiências vivenciadas, que surtem efeitos positivos no que tange à aquisição de produtos e serviços turísticos. Salienta-se que as informações são repassadas sem 0 objetivo de transacionar bens ou serviços, mas apenas como uma contribuição voluntária entre os interagentes das comunidades virtuais.

Palavras-chave: Comunidades virtuais; Marketing; Internet; Turismo. 


\title{
Virtual communities as environment builders for marketing strategies: locus for information and exchange of real experiences
}

\begin{abstract}
This research aimed at investigating the potentiality of the utilization of virtual communities as a source of information for marketing strategies in the tourism sector. A qualitative research with on-line focus groups was utilized. The results showed that people exchange real experiences and that this spontaneous collaboration has positive effects on acquisition of tourist products and services, even though information is passed on without the objective of negotiating goods or services, but only as a voluntary contribution between inter-agents in virtual communities.
\end{abstract}

Key-words: Virtual communities, marketing, internet, tourism.

Recebido em 21.02.2008 Aceito 13.10.2008

\section{Introdução}

As tecnologias modificam algumas dimensões da inter-relação do indivíduo com o mundo, da percepção da realidade, da interação com o tempo e o espaço. Cada inovação tecnológica bem sucedida modifica os padrões de lidar com a realidade e o patamar de exigências em relação à informação. O desenvolvimento dos meios de comunicação cria novas formas de ação e de interação, e novos tipos de relacionamentos sociais. Neste novo contexto, a interação se dissocia do ambiente físico, de tal maneira que os indivíduos podem interagir ainda que não partilhem do mesmo ambiente espaço-temporal (THOMPSON, 2002).

Diante disso, o indivíduo sai à procura de pessoas com as quais possa compartilhar interesses em comum, ação que se repete, uma vez que é da natureza humana relacionar-se socialmente. Neste cenário, as comunidades virtuais destacam-se como agrupamentos humanos constituídos no ambiente virtual ou ciberespaço - como alguns preferem denominar. Com $o$ uso das novas tecnologias de informação e comunicação, destacando-se a internet, o marketing está evoluindo no sentido de abrangência e de possibilidade de interação entre empresa e consumidores, utilizando-se de comunidades virtuais. Neste sentido, a 
teoria de marketing passa da comunicação de massa para um enfoque de relacionamento, interatividade e troca de experiências vivenciadas.

Diante do exposto, objetivou-se investigar a potencialidade do uso de comunidades virtuais como fonte para estratégias mercadológicas no setor de turismo; identificando o perfil dos membros de comunidades virtuais relacionadas com turismo, observando como ocorrem as trocas de informações entre seus membros e verificando $o$ impacto que as informações obtidas de forma interativa nas comunidades virtuais podem influenciar nas decisões de consumo de produtos turísticos.

O estudo focaliza o uso da internet e o setor turístico, uma vez que ambos estão em crescimento, e também porque a internet e o turismo são áreas em que a interatividade pode tornar-se fundamental. Por meio de sistemas de informação interativos, estruturados em torno do lazer, pode-se levar as empresas de turismo a uma maior interatividade com seus clientes. Destarte, a troca de informações e de experiências vivenciadas, utilizando-se de comunidades virtuais, é uma forma de interatividade cliente/empresa e cliente/cliente.

\section{Fundamentação teórica}

\subsection{Da comunidade de base territorial para a comunidade de grupos sociais por escolha}

Para a maioria dos seres humanos, historicamente, a filiação a uma comunidade não é o resultado de uma escolha deliberada, mas uma questão de história e tradição. A maioria das comunidades, através dos tempos, pode ser descrita, conforme Goldsmith (1998, p. 114), como 'comunidades compulsórias'. A comunidade podia rejeitar um membro muito mais facilmente do que ele podia rejeitar a comunidade.

Martin Buber, em seu livro 'Sobre comunidades', apresenta a principal diferença entre elas e a dificuldade de se conceituar comunidade e sociedade. Buber (1987, p. 16), baseando-se em Ferdinand Tönnies, observou que "a principal diferença entre os tipos, intitulados por ele, respectivamente, gemeinschaft (comunidade) e gesellschaft (sociedade ou associação), repousa na existência de dois tipos de 'vontades', qualitativamente diferenciados e opostos". Assim, a mudança social, de acordo com Tönnies, seria fruto de dois princípios aparentemente conflitantes: "o aristotélico de que o homem é um ser social e o hobbesiano, no qual o homem é de natureza anti-social". Estes dois princípios constituiriam a natureza contraditória do homem (CAHNMAN, 1995, p. 91). O ser humano, portanto, "aspiraria à união e, ao mesmo tempo, seria contra ela, oscilaria entre a conexão e a separação, o coletivo e o individual" (ТÖTÖ, 1995, p. 50).

Assim, a idéia de comunidade moderna começou a se distinguir de seu protótipo antigo, apoiando-se em diferentes princípios de coesão entre os seus elementos constituintes, em contraste entre, de um lado, parentesco e território, e de outro, sentimentos e interesses. A 
humanidade, observa Buber (1987, p. 39), "que teve sua origem em uma comunidade primitiva obscura e sem beleza e passou pela crescente escravidão da 'sociedade', chegará a uma nova comunidade que, diferentemente da primeira, não terá mais como base laços de sangue, mas laços de escolha".

Destarte, a possibilidade de o indivíduo interagir através da internet, encurtando as distâncias geográficas a ponto de torná-las insignificantes, estaria nos levando a um novo e abrangente processo, como intitula Lévy (1996), de 'desterritorialização'. Assim, as novas tecnologias, as novas formas organizacionais e o surgimento da comunicação de forma global exercerão um profundo efeito no senso de comunidade nos próximos anos (ROVAI e WIGHTING, 2005; KUCUK e KRISHNAMURRTHY, 2007). Desse modo, também a comunicação mediada por computador (CMC) está influenciando a vida das pessoas e a noção de comunidade. Por isso, muitos autores, como Goldsmith (1998), Rheingold (1998), Castells (1999), Ridings et al. (2002), Moor e Weigand (2007), optaram por definir as novas comunidades como 'comunidades virtuais'.

Rheingold (1996, p. 18) define comunidade virtual "como um agregado social que surge na Internet, quando um conjunto de pessoas leva adiante discussões públicas longas o suficiente, e com suficiente emoção, para estabelecerem redes de relacionamentos no ciberespaço". Para Castells (1999, p. 385), a comunidade virtual é uma "rede eletrônica de comunicação interativa e organizada em torno de um interesse ou finalidade compartilhada, embora algumas vezes a própria comunicação se transforme no objetivo". A comunidade pressupõe relações entre os seus membros - a interatividade, que não é uma característica do meio, mas a extensão em que as mensagens, em uma seqüência, relacionam-se umas com as outras, especialmente na extensão em que mensagens posteriores têm relação com as anteriores.

O sentimento de pertencimento é outro elemento presente na comunidade virtual. Ele é explicado por Palacios (2003) como um sentido de ligação. Este sentimento para com a comunidade pode ser encontrado nas noções de gemeinschaft, de Tönnies, ou mesmo na comunidade emocional de Weber (1987), e é visto como condição necessária para a existência de comunidade no ciberespaço. Contudo, o que interessa, lembra Recuero (2001), é não somente analisar como se formam esses laços on-line, mas também em que medida eles afetam a vida off-line das pessoas.

Apesar da dificuldade de conceituar comunidade virtual, têm-se apresentado soluções e argumentos consistentes para a utilização do conceito no ciberespaço. Apesar da modificação de algumas noções na idéia de comunidade off-line, os elementos são semelhantes. A comunidade virtual é um elemento do ciberespaço, mas existe apenas enquanto as pessoas realizam trocas e estabelecem laços sociais. Este sentimento de 'pertencer' parece estar sendo valorizado de uma forma diferente nestes novos grupos presentes em ambiente virtual. Ao que parece, é justamente esse sentimento que se torna primordial para que a 
comunidade virtual se mantenha ativa. O seu estudo busca a compreensão de como as novas tecnologias de comunicação estão influenciando e modificando a socialização das pessoas, e das estratégias mercadológicas neste novo contexto.

\subsection{Influências no comportamento do consumidor}

Com a expansão do capitalismo, que trouxe a produção em massa, o conceito de marketing tornou-se cada vez mais relevante dentro das empresas, constituindo um tema atual que tem merecido grande atenção dos teóricos clássicos de marketing. Entre eles, destacam-se: Hunt (1976, 1990), Kotler (1972), Sheth et al. (1988), Shaw e Jones (2005).

A evolução do conceito de marketing é passível de uma primeira classificação, simplificada, que destaca as principais fases do seu estudo: Orientação para produção (até meados de 1920); Orientação para vendas (entre 1920 a 1950); Orientação para marketing (de 1950 até o presente); e Orientação para o marketing de relacionamento (de 1990 em diante). O debate na atualidade é sobre o uso do marketing de relacionamento, marketing experiencial, cybermarketing, marketing na internet, que está mudando os hábitos de comunicação e consumo e as formas de implementações de ações estratégicas.

As pessoas que se encontram no ciberespaço podem fazer quase tudo que elas fazem no mundo social local: freqüentar espaços comuns, discutir sobre assuntos comuns e conhecer pessoas com os mesmos interesses. Para Karsaklian (2004), por mais que se busque conhecer o consumidor, é difícil saber quais comportamentos ele vai ter em relação a fatos que venham a ocorrer durante a sua vida. No mercado, as pessoas passam por etapas na decisão de compra: são processos para a satisfação de suas necessidades. Pode-se dizer que o consumo é composto de influências para a compra e que o consumidor determina o seu consumo, conforme sua posição econômica e cultural dentro da sociedade.

Assim, a pessoa fica pronta para agir, influenciada por outros na sua percepção, o que poderá determinar sua decisão de compra. Desse modo, o consumidor percorre várias etapas até fazer escolhas sobre produtos e serviços. O comportamento do consumidor no momento da compra é influenciado por importantes processos decisórios, que não podem deixar de ser investigados.

No processo de tomada de decisão de consumo, alguns autores destacam cinco estágios pelos quais os consumidores passam quando estão fazendo uma operação de compra: reconhecimento do problema, busca de informações, avaliação de alternativas, decisão de compra e comportamento pós-compra ou uso (SOLOMON, 2002; KARSAKLIAN, 2004).

Dos estágios acima, em pelo menos dois a influência social direta ou indireta de outros compradores e/ou consumidores - que podem ser classificados como formadores ou líderes de opinião - afetará seu processo de decisão de compra. Paralelamente, existem pessoas que ativamente 
procuram informação e conselho sobre produtos, às vezes chamados de 'buscadoras de opinião' ou 'recipientes de opinião'. Complementando, os formadores de opinião "são fontes de alta credibilidade para informações relacionadas a produtos porque comumente são percebidos como objetivos em relação à informação ou ao conselho que fornecem". Suas "intenções são vistas como voltadas para o melhor interesse dos recipientes de opiniões, porque eles não recebem compensação financeira pelo conselho e aparentemente não têm qualquer interesse pessoal em dá-Io" (SCHIFFMAN e KANUK, 2000, p. 354). Destarte, os formadores de opinião são fontes tanto de informação como de conselho. Eles podem simplesmente 'conversar' sobre suas experiências com um produto/serviço, 'relatar' o que sabem sobre um produto/serviço ou, mais agressivamente, 'aconselhar' os outros a comprarem ou a evitarem determinado produto/serviço.

Portanto, o conhecimento dos fatores influenciadores que movem atitudes e comportamentos dos consumidores pode ajudar a detectar as oportunidades no mercado. Nos termos de Hamel (2000), quebra-se o paradigma do marketing tradicional, pelo qual se vê o cliente como alvo, e passa-se a enxergá-lo como um indivíduo interativo. Para atingir esses objetivos, a instituição deve optar pela implantação de um modelo de gestão de marketing interativo, auxiliado por um sistema informacional detalhado e dinâmico.

Assim, observa-se que somente a tecnologia não muda ou acrescenta ao estudo do composto de marketing, mas sim a interação humana de relacionamento, por meio da redução da 'frieza' das máquinas, acrescentando a presença humana pela interatividade no ambiente on-line em tempo real. Com esta interação entre os consumidores e as empresas, bem como entre outros consumidores no ambiente on-line, destaca a comunidade virtual, que dará credibilidade às informações apresentadas, podendo despertar o interesse de outros possíveis clientes. Isso porque a teoria do comportamento do consumidor enfatiza o aspecto de fatores influenciadores e, assim, as recomendações e informações serão bem aceitas a partir do momento em que exista um grupo de confiabilidade.

\subsection{Comunidades virtuais como estratégia de marketing no setor de turismo}

O turismo é reconhecido como uma atividade econômica de importância global, haja vista a atenção dada a ele pelos governos e organizações, tanto do setor público como do privado, e acadêmicas (BENI, 2000). O Brasil, apesar de possuir um grande potencial turístico, ainda ocupa uma posição discreta, se comparado ao fluxo turístico de outros países (SCHLÜTER, 2003). A atividade econômica resultante do setor de turismo é uma importante fonte geradora de empregos e de renda.

Contudo, é importante entender o produto turístico, pois ele possui características próprias e peculiares que o particularizam e o diferenciam 
dos produtos industriais e comerciais. Entre as singularidades, podem-se citar a necessidade da clientela no local da produção, já que o produto turístico não tem como ir até o turista; a impossibilidade de estocagem; sua forma abstrata, já que é impossível fornecer uma amostra do produto ao cliente, e sua forma estática (DE ROSE, 2002), sendo um bem de consumo abstrato (RUSCHMANN, 1991). Assim, uma de suas características mais marcantes é o fato de tratar-se de um produto imaterial - intangível - cujo resíduo, após o uso, é uma experiência vivencial. Do mesmo modo, para Lage e Milone (2001, p. 51), as atrações, as facilidades e acessibilidades são partes integrantes do produto turístico.

A dinâmica da internet como um meio de comunicação leva contida a fundamentação do marketing: expansão da informação. O ponto principal do uso de comunidades virtuais como estratégia de marketing é o fornecimento de conteúdo. Quinn e Voyer (2001) afirmam que os processos de formação de estratégias envolvem estudar, questionar, perguntar, ouvir e falar, evitando compromissos irreversíveis. Portanto, a lógica manda que se inclua intencionalmente flexibilidade para agir, na medida em que os eventos exijam. Por fim, explicitam a necessidade de se reconhecer que a estratégia não é um processo linear e que sua validade consiste na capacidade de captar a iniciativa, lidar com eventos imprevisíveis, redistribuir e concentrar recursos à medida que novas oportunidades e novos impulsos venham a emergir. Assim, a internet, e em especial as comunidades virtuais, pode liderar eficientemente a tendência da evolução do marketing e permitir que se ofereça mais, e não menos, informação (VESCOVI e ISEPPON, 2002).

As comunidades virtuais têm o seu valor derivado da possibilidade de prover os consumidores com a habilidade de interagirem entre si e, assim, satisfazer às suas múltiplas necessidades sociais e comerciais. As comunidades virtuais podem desempenhar um papel preponderante no fortalecimento da identidade de marca (SCHNEIDER e BOWEN, 1999).

O entendimento da formação de grupos é fundamental nos estudos de comportamento de consumidor, visto que um grupo é um conjunto de indivíduos que interagem entre si durante algum período de tempo e compartilham uma necessidade ou objetivo comum. Assim, o próprio grupo serve como um meio para alcançar um objetivo (ENGEL et al. 2000), e as pessoas estão na rede principalmente porque valorizam e gostam da interatividade da comunicação eletrônica (WANG et al. 2002, HSU et al. 2007).

Nesse sentido, a internet pode ser considerada um espaço onde as pessoas se agrupam em comunidades, que vislumbram a interação, que por sua vez pode se reverter em ações cooperativas entre os interagentes. Assim, pode-se enumerar a uniformidade de aplicações que existem em toda a rede, independentemente do local ou país onde se utilize, como os custos reduzidos para acessar a informação e os diversos recursos de informação sobre qualquer assunto (BUHALIS e LICATA, 2002; SHARMA e SHETH, 2004). 
Como o turismo, na visão do cliente até o momento de vivenciá-lo, é somente o conjunto de informações e expectativas, a internet e o turismo têm uma sinergia potencial. A internet mostra-se uma ferramenta estratégica de impacto, causando mudanças e levando as empresas a repensarem seus modelos de negócio.

Os produtos informacionais geram retornos crescentes. Diferente de outros bens, o conhecimento aumenta de valor conforme é usado. Percebe-se que um produto informacional custa muito para ser produzido, mas muito pouco para se reproduzir. Assim, observa-se a possibilidade do uso da internet, por meio de comunidades virtuais, como meio possível de formação de estratégias de forma interativa entre empresas e clientes. 0 uso da tecnologia aumenta o valor para o cliente porque reduz o custo dos produtos, propicia novos produtos e aperfeiçoa os já existentes.

3 Procedimentos Metodológicos

Visando atender aos objetivos propostos na pesquisa, foi utilizado um método qualitativo para a coleta de dados, baseando-se em Chizzotti (2000). Na primeira etapa deste estudo, um questionário on-line estruturado foi aplicado objetivando levantar o perfil dos usuários de comunidades virtuais. Tal questionário vislumbrou coletar informações que serviram de base para a elaboração do roteiro que deu suporte à aplicação da técnica de grupos focais on-line ${ }^{1}$, que foi utilizada na segunda parte da coleta de dados da pesquisa.

Os grupos focais on-line foram realizados a fim de complementar as informações coletadas no questionário, bem como de levantar dados de maior subjetividade, necessários ao objetivo da pesquisa.

Após uma seleção prévia, e baseando-se nos resultados da primeira etapa, solicitou-se autorização do moderador das comunidades virtuais e repassou-se o convite ${ }^{2}$ aos membros para participarem de um debate via internet (grupo focal on-line). Nas datas estabelecidas, os participantes acessaram o endereço do site e usaram o nome de usuário para entrar na sala de debate predefinida pelo pesquisador. Uma dinâmica de apresentação foi estabelecida pela moderadora, a fim de que todos os participantes tivessem algum tipo de conhecimento sobre os demais. Na seqüência, a moderadora digitou as questões pré-estabelecidas, determinando um tempo para que os participantes pudessem responder e questionar a moderadora, o pesquisador bem como os outros membros do debate. Destacam-se alguns dos tópicos abordados: se as trocas de informações e experiências nas comunidades eram como usuário ou como especialista da área de turismo; se estas trocas de informações

\footnotetext{
${ }^{1} \mathrm{O}$ grupo focal teve origem na sociologia, e hoje é amplamente utilizado na área de marketing (AAKER et al. 2001). Os grupos focais são pequenos grupos de pessoas reunidas para avaliar conceitos ou identificar problemas, constituindo-se em uma ferramenta comum usada em pesquisas de marketing para determinar as reações dos consumidores a novos produtos, serviços ou mensagens promocionais. Trata-se de uma técnica de pesquisa qualitativa composta por pequenos grupos de pessoas que se reúnem para discutir um tópico específico. O propósito do grupo focal é gerar idéias, opiniões, atitudes e perspectivas (CHASE e ALVAREZ, 2000; SWEET, 2000; BROWN, 2002). Com o advento de novas tecnologias de comunicação e informação, os grupos focais começaram a utilizar as salas virtuais. E essa nova modalidade - grupos focais on-line - tem sido alvo de estudos de teóricos como Walston e Lissitz (2000); Sweet (2001) e Underhill e Olmsted (2003).

${ }^{2}$ A participação em grupos focais on-line somente ocorre mediante convite.
} 
influenciavam em suas decisões; sobre a confiabilidade das informações obtidas; sobre o uso de sites especializados.

A interação variou entre 1 hora e 5 minutos e 1 hora e 30 minutos. Um rascunho da transcrição ficou pronto no fim de cada sessão, necessitando-se apenas copiar e colar no editor de texto utilizado pelo pesquisador. Esta é uma das vantagens do método de grupo focal on-line em relação ao método tradicional (face to face), em que vários dias são necessários para a transcrição (CHASE e ALVAREZ, 2000; GILL, 2003; STRICKLAND et al. 2003; SWEET e WALKOWSKI, 2000; SWEET, 2001). Destaca-se também a adequação da utilização do ambiente on-line para a coleta de dados, uma vez que o enfoque do estudo se dá justamente na interação entre indivíduos em ambiente virtual e seus possíveis reflexos no planejamento de marketing das organizações.

Para tratamento e análise dos dados coletados nos grupos focais online, foi utilizada a metodologia de análise do discurso ${ }^{3}$. As informações obtidas nos questionários, bem como nos grupos focais, puderam ser cruzadas e analisadas, levando-se em considerações aspectos sociais, cognitivos, entre outros. Com relação à amostragem, ela foi caracterizada como não probabilística ${ }^{4}$.

Para definir o número de participantes dos grupos focais on-line foram utilizados critérios adotados em estudos já realizados (MONOLESCU e SCHIFTER, 1999; WALSTON e LISSITZ, 2000; CHASE e ALVAREZ, 2000; SCHIFFMAN e KANUK, 2000; ADLER e ZARCHIN, 2002; BURTON e GOLDSMITH, 2002; MACLARAN e CATTERALL, 2002; MOLONEY et al., 2003; STRICKLAND et al., 2003; UNDERHILL e OLMSTED, 2003), que variaram entre 4 e 12 participantes.

Desse modo, para cada grupo focal foram convidados entre 4 e 8 membros, quantidade considerada satisfatória ${ }^{5}$.

Assim, foram estudados cinco grupos focais on-line que contaram com os seguintes números de participantes: três grupos com quatro participantes, um grupo com cinco e outro com seis participantes. Visando complementar as informações obtidas na pesquisa quantitativa (primeira fase), adquiriu-se um resumo do perfil de usuários da internet, do Instituto Brasileiro de Opinião Pública e Estatística - IBOPE/NetRatings (2005).

\footnotetext{
${ }^{3}$ Tal técnica implica em buscar bases epistemológicas e conceituais que indiquem caminhos para a apreensão dos fenômenos estudados. É voltada especialmente para a analise qualitativa e baseada nos princípios da concepção múltipla da realidade, que busca as relações e correlações, interroga sobre a intencionalidade das ações, leva a uma pesquisa participativa e aproxima-se mais do real (GILL, 2003; VAN DIJK, 2004; CORIOLANO, 2005). Cappelle et al. (2003) ressaltam que a linguagem está marcada pelo conceito de social e histórico - sua interação entre o homem e a realidade natural e social.

${ }^{4}$ Segundo um critério de julgamento do pesquisador, tendo como base o que acredita que os elementos selecionados possam fornecer ao estudo. Segundo Gondim (2003, p. 158), a "representatividade estatística não é o mais importante", o que importa é a "busca a explicações e os nexos causais necessários para proceder a generalizações", nas análises das discussões em grupos focais.

${ }^{5}$ A variação no número de participantes (4 e 8 membros) evita que ocorra falha no processo, como um problema no computador (máquina) ou na conexão, ou mesmo a ausência dos convidados, pois, tanto na metodologia face to face quanto na on-line, há um percentual de não participação, é comum que a desistência varie de $10 \%$ a $50 \%$, como nos estudos dos autores supracitados.
} 


\section{Resultados e discussão}

\subsection{Perfil e razões que motivam a participação em comunidades virtuais}

O perfil dos participantes de comunidades virtuais que discutem sobre turismo foi obtido por meio de um questionário on-line. Ressalta-se que os resultados obtidos são condizentes com outras pesquisas de instituto de renome nacional, como o IBOPE (2005).

Este perfil corresponde a pessoas na faixa etária média de 25 anos, na maioria solteiras, nível de escolaridade variando entre universitários e graduados, com renda mensal entre 6 e 10 salários mínimos e família com até 4 membros, em média.

É importante destacar que dois tipos de usuários de comunidades virtuais foram identificados (figura 1), denominados neste estudo especialistas e usuários consumidores. Portanto, a identificação de tais características é significante, visto que estes participantes de comunidades virtuais buscam informações diferenciadas, mesmo que algumas possam ser coincidentes.

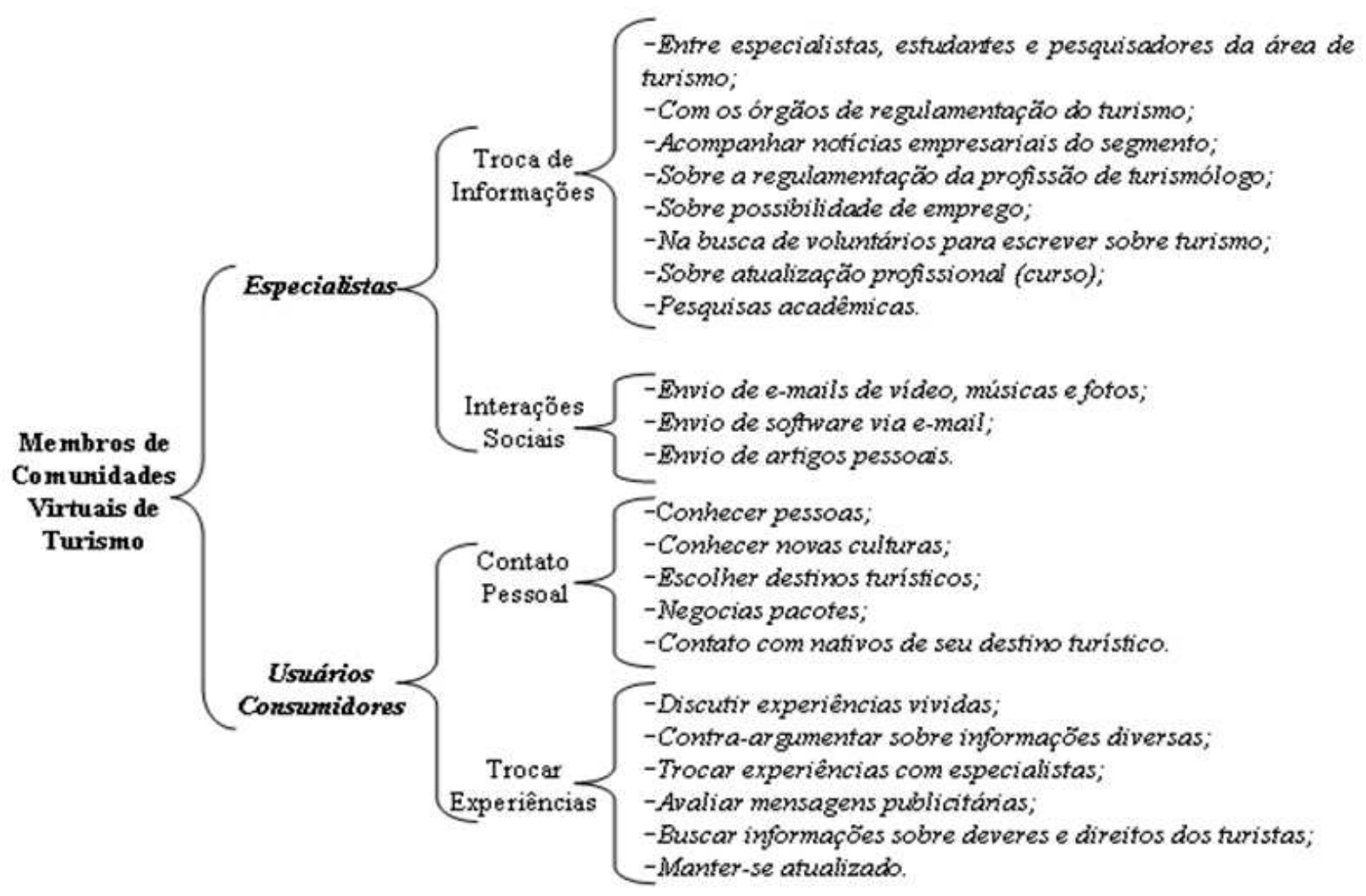

FIGURA 1: Tipos de membros e motivos do pertencimento à comunidade virtual de enfoque turístico.

Fonte: Dados da pesquisa.

Assim, em geral, os especialistas procuram trocar informações sobre aspectos profissionais, visando aperfeiçoar seus conhecimentos, 
bem como utilizam as comunidades virtuais para debater o fortalecimento do setor turístico, por meio de experiências e exigências legais, para que não ocorram desvios de atuação dos atores envolvidos no segmento turístico. Verificou-se também que alguns 'especialistas' utilizam as comunidades virtuais para desenvolver e apresentar suas habilidades pessoais, e, desse modo, aumentar sua rede de relacionamento, objetivando destacar-se no mercado.

Os usuários consumidores buscam nas comunidades virtuais formas de interações sociais, mantendo contato com pessoas de diversas áreas e locais, criando, assim, novos laços de amizade no ambiente on-line. Constatou-se também que os 'usuários consumidores' participam de comunidades virtuais sobre turismo e as utilizam para trocar experiências sobre destinos turísticos, pois os depoimentos das pessoas que visitaram determinado ponto turístico repassam mais credibilidade do que uma mensagem publicitária. Portanto, os depoimentos e os relatos de experiências vivenciadas feitos em comunidades virtuais permitem às pessoas analisarem e tomarem suas decisões de consumir ou não determinado produto/serviço, visto que alguns consumidores têm receio em relação às informações repassadas pelas empresas do segmento turístico. Portanto, os consumidores dotam-se de empowerment através das comunidades virtuais, não precisando aceitar regras e valores ditados pelas organizações.

Quando à indagação sobre quais as razões que levaram os participantes a participarem de tais comunidades, entre as respostas destacaram-se a troca de experiências (76,9\%), seguida do interesse em conhecer pessoas, que também resulta em uma forma de buscar novos conhecimentos e novas experiências.

Vale destacar que o tempo médio mensal de uso residencial da internet entre os brasileiros aposentados é de 29 horas e 45 minutos (IBOPE/NetRatings, 2005).

De acordo com os entrevistados, $41,3 \%$ já tiveram sua decisão de consumo de produtos turísticos influenciada pelas informações obtidas em comunidades virtuais, enquanto $47,6 \%$ não foram influenciados e o restante não opinou.

Os participantes que se revelaram influenciados por interação em comunidades virtuais - homens e mulheres - destacaram que esta é uma nova maneira de obter informações para conhecer melhor seus destinos turísticos, e para evitar frustrações na aquisição de produtos/serviços turísticos. Já nas afirmações dos participantes que se declararam não influenciados pelas comunidades virtuais, prevaleceram os argumentos de que ainda não precisaram de informações turísticas ou já possuíam fontes seguras para buscar informações sobre produtos/serviços turísticos. No entanto, a maioria afirmou que utiliza as comunidades virtuais para obter outras informações que ajudem na tomada de decisão. 


\subsection{As trocas de informações entre os membros de comunidades virtuais de turismo}

Esta etapa da pesquisa analisou a potencialidade das comunidades virtuais de turismo como ambiente estratégico de marketing para o segmento turístico, investigando as interações ocorridas nesse ambiente e buscando observar as trocas de informações entre seus membros, a fim de evidenciar a influência direta e indireta dessas informações trocadas nas decisões de consumo de produtos/serviços turísticos de seus membros. A seguir são apresentadas algumas transcrições ipsis litteris mais importantes abordadas nos grupos focais on-line.

Quando indagados pela moderadora se as comunidades virtuais influenciam no processo de tomada de decisão de consumo de produtos ou serviços turísticos, alguns participantes se posicionaram negativamente quanto a tal possibilidade. Entretanto, na interação grupal, os resultados apontam para outro sentido, conforme transcrição abaixo:

M.L. Fala para Todos - Não me influenciam, pois as pessoas dão dicas irreais.

M.L. Fala para Todos - $O$ enfoque do turismo precisa atingir o visual, auditivo atraindo para a cinestesia (que é a visita pessoal)

R.F. Fala para Todos - É esta a função das imagens não?

Moderadora Fala para Todos - Influenciar ou ilustrar, R.F.?

R.F. Fala para Todos - Pela ilustração acaba influenciando ou não

R.F. Fala para Todos - As imagens e dados apresentados poderão chamar minha atenção ou não ... vai depender do trabalho apresentado.

V.L. Fala para Todos - Particularmente só confio quando existe uma fonte para eu poder checar a info

I.R. Fala para Todos - Concordo - por isso deve-se pedir contatos adicionais.

R.F. Fala para Todos - Eu geralmente confio nas informações colocadas ....

R.F. Fala para Todos - Por isso q um site com boas informações e bem feito sobre turismo (imagens) é necessário ..

Verificam-se, neste contexto, as influências grupais, onde, em um primeiro momento, um participante, considerando sua experiência vivida, argumenta a falta de credibilidade das informações obtidas das interações sociais no ambiente virtual. Todavia, a interação no mesmo ambiente demonstrou que a influência interpessoal altera a opinião dos interagentes, em vistas dos fatos apresentados. A dimensão da possibilidade de interagir no ciberespaço permite ao indivíduo uma reflexão da sua realidade interativa. Assim, as influências grupais, a aceitação e a interação social, os processos de identificação e internalização são fatores de mudança de atitudes, o que resulta em 
muitos casos na participação desprovida de preconceitos nas comunidades virtuais.

Vale destacar também que, no tocante ao aspecto temporal, foi observado no grupo focal on-line que a percepção das pessoas em relação à época do consumo varia de acordo com alguns aspectos, conforme declarado, '[...] R.E. Fala para Todos - por exemplo, no momento não posso fazer turismo como gostaria ... mas estou me preparando para quando puder', referindo-se à sua futura e breve aposentadoria. Logo, o aspecto de temporalidade é significativo nas interações dos interagentes, seja na mudança de atitude e de adaptação conforme um planejamento futuro, ou seja pela eliminação de preceitos iniciais devido às informações diferenciadas obtidas no grupo de convivência social 'off line'.

Salienta-se que os debates dos grupos focais complementamse uns aos outros, pois os participantes afirmaram que, com as informações obtidas em comunidades virtuais ou via sites especializados, o turista ganha a liberdade de escolha, afirmando que: [...] 'R.E. Fala para Todos - Por isso penso que é interessante pesquisarmos o destino que queremos conhecer e fazer nosso próprio tour ${ }^{6}$. Assim, percebe-se que os participantes, além de receber as informações de parceiros da comunidade, podem verificar sua confiabilidade através de pesquisa na própria internet, tendo autonomia para fazer seus roteiros, com um risco menor do que quando realizado apenas com base em informações de mensagens publicitárias de empresas do setor de turismo, haja vista que a internet permite uma visualização prévia do destino desejado.

É relevante considerar que, devido à naturalidade do debate, com pouco tempo de comunicação, já que não se conheciam anteriormente ao grupo focal, as três mulheres participantes já estavam se tratando com maior intimidade, utilizando apelidos:

C.D. Fala para Todos - nem devemos, Pat.

C.D. Fala para Todos - q comunidade é essa Grazi

P.W. Fala para Todos - a tab costumo consultar o guia 4 rodas grazi.

S.M. Fala para Todos - qual sua área, pat?

Por essa característica que se formou no grupo, levando-se em consideração que as participantes haviam se conhecido há menos de duas horas, pôde-se observar um vínculo razoável de amizade e liberdade de comunicação e interação, o que, ocorrendo em comunidades virtuais, é de suma importância no tocante à confiabilidade das informações repassadas e recebidas. Esta atitude promove a cooperação no grupo, através da comunicação mais informal, valorização de experiências e aceitação de opiniões como contribuições construtivas.

Vale destacar aqui que grande parte dos participantes dos grupos focais on-line, apesar de declarar que as opiniões postadas em

\footnotetext{
${ }^{6}$ Grifo nosso.
} 
comunidades virtuais não influenciam, reconheceu que elas fazem pensar sobre o assunto, levando o membro de uma comunidade virtual a analisar sua posição e verificar a possibilidade de sua interpretação estar equivocada.

Assim, as comunidades virtuais servem como network, como declarou uma participante, onde os debates enfocam os aspectos referentes aos assuntos profissionais, bem como de relacionamento entre usuários consumidores. Para os profissionais, é uma forma de intercâmbio e de agenciamento e, para os demais usuários, uma maneira de obter informações sobre destinos turísticos de seus interesses.

É interessante observar que as opiniões isoladas são normalmente negativas à utilidade e aplicação de comunidades virtuais como meio confiável de informação. No entanto, no decorrer do debate, e com os argumentos desenvolvidos, as pessoas descrevem situações e opiniões diferentes, demonstrando, assim, a potencialidade do uso da internet e, em especial, das comunidades virtuais, para promover mudanças nos indivíduos. Isso porque as mesmas permitem ao indivíduo fazer novas avaliações do que está sendo abordado e apresentar novas formas de pensar sobre o tema debatido, recebendo influência dos demais membros conforme discussão a seguir.

VIR Fala para Todos - Eu amo viajar mas nunca encontrei uma comunidade interessante

VIR Fala para Todos - sempre se acha alguma utilidade

VIR fala para Todos - é mto relativo pois depende do gosto, idade e $n$ coisas de quem esta sugerindo

VIR Fala para Todos - hj em dia com a www, td ficou mto mais fácil

VIR Fala para Todos - podemos colocar qq empresa no fogo e eles sabem disto

Traçando-se uma breve visão geral das discussões dos grupos focais on-line realizados nesta pesquisa, pode-se verificar que os dados obtidos apontam para: deficiências em empresas do segmento turístico, problemas de regulamentação, desconhecimento por parte dos turistas de seus direitos e desconfiança nas informações disponibilizadas na internet, mesmo sendo estas em comunidades virtuais de interesse específico, como no caso do setor de turismo.

Vale mencionar que, entre os aspectos relevantes na área de marketing, estão fatores culturais e sociais do consumidor que, por vezes, são desconsiderados pelas empresas e profissionais ligados ao setor turístico. Esse desconhecimento de práticas sociais e culturais do país de seu destino turístico pode expor o turista a situações desagradáveis nas suas férias ou negócios, bem como à transgressão de costumes locais, descumprimento e violações de aspectos legais nacionais, involuntariamente. As comunidades virtuais podem suprir essas deficiências, disponibilizando informações aos turistas, por meio das 
experiências vivenciadas por seus membros e também através das estratégias de comunicação das empresas do segmento envolvido.

Um ponto que vale destacar para complementar as considerações dos grupos refere-se à sugestão de qualificação de comunidades virtuais, como ocorre em sites de comércio eletrônico, como Mercado Livre ${ }^{7}$, Ebay etc., apenas para citar alguns exemplos. Desse modo, desenvolve-se uma maneira de aumentar a confiabilidade das informações obtidas em comunidades virtuais. Assim, enfatizam-se as palavras de uma participante do quinto grupo focal on-line, apontando que as comunidades virtuais podem ser descritas como 'marketing de informações', onde as pessoas disponibilizam informações, sem interesses de retornos financeiros, mas apenas como forma de intercambiar experiências pessoais.

Portanto, os dados obtidos no estudo expõem a potencialidade do uso de comunidades virtuais como ambiente estratégico para 0 desenvolvimento de ações mercadológicas, por meio das interações entre os indivíduos participantes, que favoreçam o aumento da confiabilidade das informações com base nas discussões ao longo do tempo.

\section{Considerações finais}

"A Revolução Industrial foi para os produtores o que a Revolução Digital é para os consumidores" (KUCUK e KRISHNAMURTHY, 2007, p. 47). Na internet, a tecnologia empregada funciona como força impulsionadora da criatividade humana, da imaginação, devido à visibilidade e à disponibilidade de material que circula na rede, permitindo que a comunicação se intensifique. Ou seja, as ferramentas promovem o convívio, o contato, enfim, uma maior aproximação entre as pessoas, entre outras tantas possibilidades.

Observou-se neste estudo que os membros de comunidades virtuais sobre turismo realizam trocas de informações espontaneamente, apresentando dados e suas experiências sobre produtos e serviços turísticos aos demais participantes. Desse modo, gera-se um debate interativo sobre o tema em questão e cada um toma sua decisão de consumir ou não determinado produto/serviço turístico, levando em consideração as informações obtidas, suas exigências e expectativas, suas referências e experiências pessoais, dependendo do seu nível cultural. Neste novo contexto, os participantes podem ter voz ativa e liberdade de argumentação, dependendo exclusivamente de seu empenho e vontade de participar de forma interativa e argumentativa nos assuntos de seu interesse.

Os resultados obtidos também demonstram que os membros de comunidades virtuais participam desta nova modalidade de interação social buscando alternativas para desenvolver novos conhecimentos e novas amizades, além de trocas de informações pessoais. Também discutem suas experiências sobre determinados produtos ou serviços

\footnotetext{
${ }^{7}$ Maiores informações sobre qualificações: http://www.mercadolivre.com.br.
} 
objetivando trocar informações, sugestões, e contra-argumentar com as empresas; e não somente a fim de receber uma mensagem publicitária para a aquisição de um produto ou serviço, sem a possibilidade de análise ou comparação. Verificou-se assim que a internet potencializa a troca de informações entre consumidores, bem como com as empresas. Ou seja, as interações ocorridas em comunidades virtuais sobre turismo influenciam no processo de tomada de decisão de consumo de produtos/serviços turísticos dos integrantes da comunidade virtual.

Percebe-se, atualmente, uma maior ênfase nos relacionamentos de interatividade nas transações comerciais entre vendedores e consumidores, em que este último faz uso das novas tecnologias para sua evolução e aplicabilidade. Portanto, uma nova abordagem deve ser criada para atender às expectativas deste exigente e bem informado público que constitui as comunidades virtuais de consumo. O uso de comunidades virtuais procura ir além da promoção de relacionamento, buscando principalmente a interatividade em tempo real e o fornecimento de informações, sem, necessariamente, a intenção de vender ou transacionar algum objeto, e sim, a de compartilhar informações.

Desse modo, trabalha-se com a informação qualificada - as experiências vivenciadas -, através da qual as pessoas buscam a experiência do outro - o relato desta experiência. Assim, as pessoas evitam o excesso de informação encontrado em sites especializados e desenvolvem o senso crítico de que a informação nestes ambientes pode ter sido construída tendenciosamente para influenciar o consumidor abordagem do marketing transacional em sites especializados. A informação obtida por meio de outros membros da comunidade virtual é distinta da encontrada em sites especializados, pois não são omitidos fatores positivos e negativos do produto/serviço turístico discutido/analisado.

No marketing transacional, a forma de transmitir a mensagem se restringe, de modo geral, a informar aspectos positivos do bem ou serviço a ser prestado, ou seja, informa e não necessariamente retrata; enquanto que na comunidade virtual, são disponibilizadas informações dos pontos positivos e negativos, permitindo ao consumidor escolher e prevenir-se de estratagema de empresários antiéticos. Estas informações são disponibilizadas por outras pessoas que passam credibilidade, porque, a princípio, elas não teriam razões para mentir.

O ponto central deste argumento é o de que a informação é obtida através de pessoas implicadas no processo de geração da mesma, pois elas transmitem informações com autoridade, devido à experiência vivenciada - dados concretos. Estas informações devem ser exploradas pelas empresas e disponibilizadas aos seus visitantes, dando, assim, credibilidade e liberdade de escolha para participar e interagir com a empresa e com os demais participantes da comunidade virtual.

Estas formas interativas de comunicação e informação podem propiciar ao segmento turístico um grande diferencial estratégico, no momento em que começarem a dialogar com seus consumidores e, ao mesmo 
tempo, em que tiverem a possibilidade de acompanhar o diálogo entre os consumidores por meio de comunidades virtuais. Justamente pelo fato da informação ter sua origem em fonte supostamente neutra, ela manifesta-se menos filtrada por mecanismos de percepção, como a exposição seletiva a mensagens e a dispersão de atenção, fenômenos mais comuns nas informações provenientes de campanhas publicitárias.

Diante do exposto, as comunidades virtuais tornam-se adequadas para a efetivação de novas possibilidades na abordagem do planejamento de marketing, a partir da observação de como seus consumidores se comportam em tais ambientes e, principalmente, de como tais interações e trocas de informação alteram seu comportamento de consumo. As comunidades virtuais possibilitam, assim, não somente o contato direto entre a empresa e o cliente, mas também a interação entre cliente/cliente.

Outro ponto a ser considerado é que, além da possibilidade de aquisição de informações imparciais por parte dos clientes, as próprias empresas podem se beneficiar, utilizando essas informações obtidas dos clientes - que relatam anseios e expectativas - para aprimorar seus produtos ou serviços e oferecê-los de forma satisfatória, ou mesmo para reparar algum possível erro cometido. Uma vez que, como se constatou neste estudo, as comunidades são fontes de informação, estes dados, se forem captados adequadamente, servirão de insumos para inovar na formulação de estratégias mercadológicas, que podem ser aplicadas não somente no setor turístico, mas também em outros ramos de atividade.

\section{Referências}

AAKER, D. A. et al. Pesquisa de marketing. São Paulo: Atlas, 2001.

ADLER, C. L.; ZARCHIN, Y. R. The 'virtual focus group': using the internet to reach pregnant women on home bed rest. Journal of Obstetric, Gynecologic, and Neonatal Nursing, Thousand Oaks, v. 31, n. 4, p. 418427, ago. 2002.

BENI, M. C. Análise estrutural do turismo. 3. ed. São Paulo: SENAC, 2000.

BROWN, N. R. 'Community' metaphors on-line: a critical and rhetorical study concerning on-line groups. Business Communication Quarterly, v. 65, n. 2, p. 92-100, June 2002.

BUBER, M. Sobre comunidade. São Paulo: Perspectiva, 1987.

BUHALIS, D.; LICATA, M. C. The future eTourism intermediaries. Tourism Management, n. 23, p. 207-220, 2002.

BURTON, L.; GOLDSMITH, D. The medium is the message: using on-line focus groups to study on-line learning. Connecticut Distance Learning Consortium, jun. $2002 . \quad$ Disponível em: 
$<$ http://www.ctdlc.org/Evaluation/mediumpaper.pdf $>$. Acesso em: 10 nov. 2008.

CAHNMAN, W. J. Tönnies e a teoria das mudanças sociais: uma reconstrução. In: MIRANDA, O. (Org.). Para Ler Ferdinand Tönnies. São Paulo: Edusp, 1995.

CAPPELLE, M. C. A. et al. Análise de conteúdo e análise de discurso nas ciências sociais. Organizações Rurais e Agroindustriais - Revista Eletrônica de Administração da UFLA, v. 5, n. 1, 2003.

CASTELLS, M. A sociedade em rede. 3. ed. São Paulo: Paz e Terra, 1999. V. 1.

CHASE, L.; ALVAREZ, J. Internet research: the role of the focus groups. Library \& Information Science Research, New York, v. 22, n. 4, p. 357369, 2000.

CHIZZOTTI, A. Pesquisa em ciências humanas e sociais. 4. ed. São Paulo: Cortez, 2000.

CORIOLANO, L. N. M. T. Epistomologia da análise do discurso no turismo. Cardeno de Turismo Virtual, Rio de Janeiro, n . 16, p. 39-45, jun. 2005.

DE ROSE, A. T. Turismo, planejamento e marketing. Barueri: Manole, 2002.

ENGEL, J. F. et al. Comportamento do consumidor. 8. ed. Rio de Janeiro: LTC, 2000.

GILL, R. Análise de discurso. In: BAUER, M. W.; GASKELL, G. (Orgs.). Pesquisa qualitativa com texto, imagem e som: um manual prático. 2. ed. Petrópolis: Vozes, 2003.

GOLDSMITH, M. Comunicações globais e comunidades por escolha. In: HESSELBEN, F. et al. (Orgs.). A comunidade do futuro. São Paulo: Futura, 1998.

GONDIM, S. M. G. Grupos focais como técnica de investigação qualitativa: desafios metodológicos. Paidéia: Cadernos de Psicologia e Educação, Ribeirão Preto, v. 12, n. 24, p. 149-161, 2003.

HAMEL. G. Liderando a revolução. 4. ed. Rio de Janeiro: Campus, 2000.

$\mathrm{HSU}, \mathrm{M}$. et al. Knowledge sharing behavior in virtual communities: the relationship between trust, self-efficacy, and outcome expectations. International Journal of Human-Computer Studies, v. 65, n. 2, p. 153169, Feb. 2007.

HUNT, S. D. The nature and scope of marketing. Journal of Marketing, Chicago, v. 40, n. 3, p. 17-28, July 1976.

. Truth in marketing theory and research. Journal of Marketing, Chicago, v. 54, n. 3, p. 1-15, July 1990. 
INSTITUTO BRASILEIRO DE OPINIÃO PÚBLICA E ESTATÍSTICA - IBOPE. Resumo da audiência de Internet domiciliar no Brasil e perfil do internauta brasileiro. Rio de Janeiro: [s.n.], 2005. 1 CD-ROM.

KARSAKLIAN, E. Comportamento do consumidor. 2. ed. São Paulo: Atlas, 2004.

KOTLER, P. A generic concept of marketing. Journal of Marketing, Chicago, v. 36, n. 2, p. 46-54, Apr. 1972.

KUCUK, S. U.; KRISHNAMURTHY, S. An analysis of consumer power on the Internet. Technovation, v. 27, n.1, p. 47-56, Jan./Feb. 2007.

LAGE, B. H. G.; MILONE, P. C. Economia do turismo. 7. ed. São Paulo: Atlas, 2001.

LÉVY, P. O que é virtual? São Paulo: Ed. 34, 1996.

MACLARAN, P.; CATTERALL, M. Researching the social web: marketing information from virtual communities. Marketing Intelligence \& Planning, v. 20, n. 6, p. 319-326, Oct. 2002.

MOLONEY, M. F. et al. Using Internet discussion boards as virtual focus groups. Advances in Nursing Science, v. 26, n. 4, p. 274-286, Oct./Dec. 2003.

MONOLESCU, D.; SCHIFTER, C. On-line focus groups: a tool to evaluate on-line students' course experience. The Internet and Higher Education, v. 2, n. 2/3, p. 171-176, 1999.

MOOR, A.; WEIGAND, H. Formalizing the evolution of virtual communities. Information Systems, v. 32, n.2, p. 223-247, Apr. 2007.

PALACIOS, M. Cotidiano e sociabilidade no ciberespaço: apontamentos para a discussão. Disponível em: $<$ http://facom.ufba.br/pesquisa/ciber/palacios>. Acesso em: 19 mar. 2003.

QUINN, J. B.; VOYER, J. Incrementação lógica: administrando a formação da estratégia. In: MINTZBERG, H.; QUINN, J. B. (Orgs.). O processo da estratégia. 3. ed. Porto Alegre: Bookman, 2001.

RECUERO, R. C. Comunidades virtuais: uma abordagem teórica. In: SEMINÁRIO INTERNACIONAL DE COMUNICAÇÃO, 2001, Porto Alegre. Anais eletrônicos... Porto Alegre: PUCRS, 2001.

RHEINGOLD, H. A comunidade virtual. Lisboa: Gradiva, 1996.

Comunidades virtuais. In: HESSELBEN, F. et al. $A$ comunidade do futuro: idéias para uma nova comunidade. São Paulo: Futura, 1998.

RIDINGS, C. M. et al. Some antecedents and effects of trust in virtual communities. Journal of Strategic Information Systems, v. 11, n. 3/4, p. 271-295, Dec. 2002. 
ROVAI, A. P.; WIGHTING. M. J. Feelings of alienation and community among higher education students in a virtual classroom. Internet and Higher Education, v. 8, n. 2, p. 97-110, 2005.

RUSCHMANN, D. V. M. Marketing turístico. Campinas: Papirus, 1991.

SCHIFFMAN, L. G.; KANUK, L. Comportamento do consumidor. São Paulo: LTC, 2000.

SCHLÜTER, R. América do Sul. In: LOCKWOOD, A.; MEDLIK, S. Turismo e hospitalidade no século XXI. Baureri: Manole, 2003.

SCHNEIDER, B.; BOWEN, D. Understanding customer delight and outrage. Sloan Management Review, Boulder, v. 41, n. 1, p. 35-45, fall 1999.

SHARMA, A.; SHETH, J. N. Web-based marketing: the coming revolution in marketing thought and strategy. Journal of Business Research, v. 57, n. 7, p. 696-702, July 2004.

SHAW, E H.; JONES, D. G. B. A history of schools of marketing thought. Marketing Theory, London, v. 5, n. 3, p. 239-281, 2005.

SHETH, J. N. et al. Marketing theory: evolution and evaluation. New York: John Wiley \& Sons, 1988.

SOLOMON, M. R. O comportamento do consumidor. 5. ed. Porto Alegre: Bookman, 2002.

STRICKLAND, O. L. et al. Measurement issues related to data collection on the world wide web. Advances in Nurses Science, Philadelphia, v. 26, n. 4, p. 246-256, Oct./Dec. 2003.

SWEET, C. Designing and conducting virtual focus groups. Qualitative Marketing Research: an International Journal, v.4, n. 3, p. 130-135, June. 2001.

SWEET, C.; WALKOWSKI, J. On-line qualitative research task force: report of findings. Quirks Market Research Review, dez. 2000. Disponivel em: $<$ http://www.quirks.com/articles/a2000/20001216.aspx?searchID $=19453$ 332\&sort $=9$ > . Acesso em: 10 nov. 2008.

THOMPSON, J. B. A mídia e a modernidade. 5. ed. Petrópolis: Vozes, 2002.

TÖTÖ, P. Fernadind Tönnies: um racionalista romântico. In: MIRANDA, O. (Org.). Para ler Ferdinand Tönnies. São Paulo: Edusp, 1995.

UNDERHILL, C.; OLMSTED, M. G. An experimental comparions of computer-mediated and face-to-face focus groups. Social Science Computer Review, Thounsand Oaks, v. 21, n. 4, p. 206-512, winter, 2003. VAN DIJK, T. A. Cognição, discurso e interação. 6. ed. São Paulo: Contexto, 2004.

VESCOVI, T.; ISEPPON, M. L'évolution d'Internet comme moyen de communication et de marketing des PMI. Revue Française du Marketing, n. 189, p. 131-40, Apr./May 2002. 
WALSTON, J. T.; LISSITZ, R. W. Computer-mediated focus groups. Evaluation Review, Thousand Oaks, v. 24, n. 5, p. 457-483, Oct. 2000.

WANG, Y. et al. Defining the virtual tourist community: implications for tourism marketing. Tourism Management, Oxford, v. 23, n. 4, p. 407-417, ago. 2002.

WEBER, M. Conceitos básicos de sociologia. São Paulo: Moraes, 1987. 